\title{
Enhanced cell-substratum adhesion of E-cadherin-expressing cells is mediated by activation of the small GTPase protein, Rac1
}

\author{
YUQING WANG $^{1,2}$, TADASHI OHKUBO ${ }^{1}$, HIROHITO TSUBOUCHI ${ }^{2}$ and MASAYUKI OZAWA ${ }^{1}$ \\ Departments of ${ }^{1}$ Biochemistry and Molecular Biology, ${ }^{2}$ Internal Medicine, \\ Graduate School of Medical and Dental Sciences, Kagoshima University, Kagoshima 890-8544, Japan
}

Received November 14, 2005; Accepted December 19, 2005

\begin{abstract}
L cell transfectants stably expressing E-cadherin demonstrate a remarkable increase in adherence to extracellular matrix proteins, such as type IV collagen and fibronectin. This enhanced adhesion is mediated by integrin-type cell surface receptors, as assessed by inhibition with anti-receptor antibodies. Both the rate and efficiency of adhesion were enhanced 4- to 5-fold. In contrast, non-specific adhesion processes, such as cell attachment to polylysine-coated substrata, are unaffected by E-cadherin expression. Thus, integrin-mediated but not non-specific adhesion is modulated by E-cadherin expression. L cells expressing mutant E-cadherin molecules either lacking the cytoplasmic domain or bearing an amino acid substitution in the $\mathrm{Ca}^{2+}$-binding motif did not exhibit enhanced adhesion. The amount of collagen receptor, the $\alpha 1$ and $\beta 1$ integrin, did not change following expression of E-cadherin. Pull-down assays with the Cdc42/Rac interactive binding (CRIB) domain of the Rac effector, p21-activated kinase, revealed increased Rac-GTP levels in cells expressing wild-type E-cadherin. These results suggest that the activation of Rac is involved in the enhancement of integrin-mediated adhesion induced by E-cadherin expression.
\end{abstract}

\section{Introduction}

Cellular adhesion to the extracellular matrix is a complex process that involves metabolic changes, cytoskeletal rearrangement and ligation of cell surface receptors specific for extracellular matrix (ECM) macromolecules $(1,2)$. The integrin family $(3,4)$ of matrix adhesion receptors is comprised of a large number of $\alpha$ and $\beta$ heterodimers. These molecules are involved in multiple cell-matrix and cell-cell adhesive processes

Correspondence to: Dr Masayuki Ozawa, Department of Biochemistry and Molecular Biology, Graduate School of Medical and Dental Sciences, Kagoshima University, Kagoshima 890-8544, Japan

E-mail: mozawa@m.kufm.kagoshima-u.ac.jp

Key words: adhesion, E-cadherin, collagen, G protein, matrix that function in neuronal, immune, connective tissue, and hematopoietic cellular systems. Mammalian receptors for fibronectin $(5,6)$, collagen, and laminin $(7,8)$ are part of the integrin superfamily. The interactions of a subset of integrins with their specific ligands can be inhibited by short peptides containing the RGD adhesive sequence (9).

It is well accepted that receptor-mediated cell adhesion is a regulated cellular process $(10,11)$. Two physiological mechanisms have been described that control the adhesion of cells to the ECM $(12,13)$. One mechanism involves modulation of the affinity of cell surface integrin receptors for ECM proteins. Divalent cations, such as $\mathrm{Mg}^{2+}, \mathrm{Mn}^{2+}$, and $\mathrm{Ca}^{2+}$, and certain anti-integrin monoclonal antibodies $(\mathrm{mAb})$ induce an increase in integrin affinity (14). The second mechanism involves an alteration of the events that follow receptor occupancy, which do not affect receptor affinity, such as cell spreading and/or integrin clustering. Treatment with phorbol esters stimulated the $\alpha 5 \beta 1$-dependent adhesion of cells onto fibronectin without altering fibronectin receptor affinity (12); this increase in cell adhesion was dependent on the actin cytoskeleton and cell spreading. The molecular mechanisms governing this increase in cell-ECM adhesion are poorly understood.

Members of the Rho subfamily of Ras-related GTPbinding proteins are critical in the regulation of cytoskeletal organization and associated focal complex formation in response to extracellular growth factors. The Rho subfamily contains several members, including Rho, Rac, and Cdc42, that cycle between the active GTP-bound state and the inactive GDP-bound state (reviewed in ref. 15). In fibroblasts, activation of Rho by extracellular growth factors, such as lysophosphatidic acid and bombesin, triggers the formation of actin stress fibers and focal adhesion complexes (16). In contrast, activation of Rac by platelet-derived growth factor, epidermal growth factor, or insulin elicits actin polymerization at the plasma membrane, producing lamellipodia and membrane ruffles (17). Activation of Cdc42 triggers the formation of filopodial protrusions and microspikes at the cell periphery $(18,19)$. Rho family GTPases are critical in the regulation of integrin clustering and the subsequent interactions of integrins with focal adhesion and signaling molecules (18). Under these conditions, attachment of fibroblasts to the ECM is not sufficient to induce the clustering of integrins and focal complex formation; the activity of the Rho GTPases, particularly Rho and Rac, is required. 
Cadherins are homophilic cell-cell adhesion molecules that bind in a $\mathrm{Ca}^{2+}$-dependent manner (20). Catenins, including $\beta$-catenin and $\alpha$-catenin, are associated with the cytoplasmic domain of cadherins $(21,22)$. Emerging evidence suggests that cross-talk may exist between the cadherins and integrins. Anti-cadherin antibodies prevent the loss of $\alpha 6$ and $\beta 1$ integrins in terminally differentiating keratinocytes (23), while introduction of E-cadherin into Xenopus-derived fibroblasts causes the downregulation of $\alpha 3 \beta 1$ integrin and a consequent reduction in adhesion to fibronectin and laminin (24). Introduction of a dominant-negative E-cadherin construct into keratinocytes results in reduced $\alpha 2 \beta 1$ and $\alpha 3 \beta 1$ integrin expression (25), while antibody blockade of $\beta 1$ and $\beta 3$ integrins leads to the $\mathrm{N}$-cadherin-dependent clustering of quail embryo neural crest cells (26). Thus, alterations in cadherin activity can have substantial effects upon the activity, level, and function of integrins.

In this report, we demonstrate that stable expression of wild-type E-cadherin but not mutant E-cadherin, either lacking the cytoplasmic domain or bearing an amino acid substitution in the $\mathrm{Ca}^{2+}$-binding motif, enhanced the adhesion of cells to dishes coated with ECM components. Pull-down of the Cdc42/ Rac interactive binding (CRIB) domain of the Rac effector p21-activated kinase in cells expressing the wild-type Ecadherin revealed increased levels of Rac-GTP, which could be responsible for the increased cell-ECM adhesion.

\section{Materials and methods}

Reagents and antibodies. Human plasma fibronectin, mouse laminin-1, mouse collagen type IV, and rat tail collagen type I were purchased from Becton-Dickinson (Bedford, MA). Rat anti-mouse CD29 (integrin B1 chain) mAb was obtained from PharMingen (San Diego, CA). Hamster anti-VLA-1 (integrin $\alpha 1$ chain) antibody was purchased from Sumitomo Denkou (Yokohama, Japan). Rabbit polyclonal anti-receptor (anti-gp140) antibodies have been previously described (27). Mouse mAbs against E-cadherin, $\beta$-catenin, $\gamma$-catenin (plakoglobin), and CDC42 were obtained from BD Transduction Laboratories (Lexington, KY). Mouse anti-Rac1 mAb and mouse anti-RhoA mAb were purchased from Upstate Biotechnology Inc. (Lake Placid, NY) and Cytoskeleton Inc. (Denver, CO), respectively. The rat $\mathrm{mAb}$ specific for $\mathrm{E}$ cadherin (DECMA-1) was kindly provided by Dr Rolf Kemler (Max-Planck Institute für Immunbiologie). Fluorescein isothiocyanate-conjugated goat anti-mouse IgG and peroxidaseconjugated goat anti-mouse IgG were obtained from Jackson ImmunoResearch Laboratories Inc. (West Grove, PA).

E-cadherin expression vectors, cells and transfection. The expression vector encoding the wild-type and mutant Ecadherin polypeptides has been described previously $(28,29)$. Full-length E-cadherin has a cytoplasmic domain of 151 amino acid residues. EC0 lacks the entire cytoplasmic domain. ED134A bears a single amino acid substitution at residue 134, which replaces an aspartic acid with alanine and abolishes E-cadherin-mediated cell-cell adhesion. L cells were transfected by the calcium-phosphate method as described (21). Cells were selected in G418-containing medium. Isolated G418-resistant cell clones were tested for expression of the transfected constructs by immunofluorescence and immunoblotting analyses. Cells were maintained in DMEM supplemented with $10 \%$ fetal calf serum containing $200 \mu \mathrm{g} / \mathrm{ml} \mathrm{G} 418$.

Adhesion assays. Falcon 24-well polystyrene tissue culture plates were coated for 1-2 h with ECM proteins in PBS at room temperature. After removal of unbound protein, the dishes were incubated with PBS containing 1\% BSA for $1 \mathrm{~h}$ at room temperature to block residual protein adsorption to the plastic. Cells were labeled overnight with $\left[{ }^{35} \mathrm{~S}\right]-$-methionine (New England Nuclear, $1000 \mathrm{Ci} / \mathrm{mmol}$ ) at $5 \mu \mathrm{Ci} / \mathrm{ml}$. After washing in PBS, cells were dissociated at $25^{\circ} \mathrm{C}$ by incubation for $10 \mathrm{~min}$ in PBS containing $0.125 \%$ trypsin and $0.01 \%$ EDTA. After washing in DMEM containing 10\% FCS, cells were resuspended in DMEM containing 1\% BSA. Cells were allowed to attach to the ECM protein-coated dishes for 1-4 $\mathrm{h}$ at $37^{\circ} \mathrm{C}$. Samples were then washed with DMEM containing $1 \%$ BSA to remove unbound cells. The residual attached cells were lysed with $2 \%$ SDS; radioactivity was quantitated in a scintillation counter. The results of the adhesion assays are expressed either as a percent of the total number of cells or as a percent of the positive control condition (adhesion to substrata in the absence of inhibitors).

Immunoblotting. Immunoblotting was essentially performed as described (30). Briefly, cells were lysed by boiling in SDS sample buffer for $5 \mathrm{~min}$. Proteins (30-50 $\mu \mathrm{g})$ were separated by SDS-PAGE and transferred to nitrocellulose membranes (Schleicher \& Schuell). Primary antibodies, diluted 1:1000, detected specific proteins, which were detected by horseradish peroxidase-conjugated secondary anti-mouse and anti-rabbit antibodies, diluted 1:1000. Proteins were visualized using the ECL-system (Amersham Pharmacia Biotech).

Detection of GTP-bound Rho family small GTPases by use of GST-CRIB. The pGEX vector encoding the Cdc42/Rac1 interactive binding region (CRIB) of $\mathrm{p} 21$-activated kinase was kindly provided by Dr Kozo Kaibuchi (Nagoya University). Experiments were performed as reported (31). Briefly, cells were washed twice in ice-cold HEPES-buffered saline (containing $20 \mathrm{mM}$ HEPES, pH 7.4, $137 \mathrm{mM} \mathrm{NaCl}$, and $3 \mathrm{mM}$ $\mathrm{KCl})$, then lysed in lysis buffer $(50 \mathrm{mM}$ Tris- $\mathrm{HCl}, \mathrm{pH} 7.4$, $10 \mathrm{mM} \mathrm{MgCl} 2,1 \% \mathrm{NP}-40,150 \mathrm{mM} \mathrm{NaCl}, 10 \mu \mathrm{g} / \mathrm{ml}$ leupeptin, $10 \mu \mathrm{g} / \mathrm{ml}$ aprotinin, and $1 \mathrm{mM}$ PMSF). The lysates were centrifuged at $15000 \mathrm{rpm}$ for $1 \mathrm{~min}$ at $4^{\circ} \mathrm{C}$; the supernatant was incubated with purified GST-CRIB immobilized beads at $4^{\circ} \mathrm{C}$ for $1 \mathrm{~h}$. The beads were washed three times in an excess of lysis buffer. Bound proteins were eluted in Laemmli sample buffer. The eluates were subjected to SDS-PAGE, followed by immunoblotting with appropriate antibodies.

\section{Results}

Effect of E-cadherin expression on efficiency and kinetics of adhesion to type IV collagen. Mouse L cells, a fibroblast cell line, do not express endogenous cadherins (32). We introduced an expression vector encoding wild-type E-cadherin into L cells and subsequently isolated multiple transfectants, from which a representative clone (EL) was chosen for experiments. L cells transfected with the neomycin gene alone, $\mathrm{nL}$ cells, were 
A
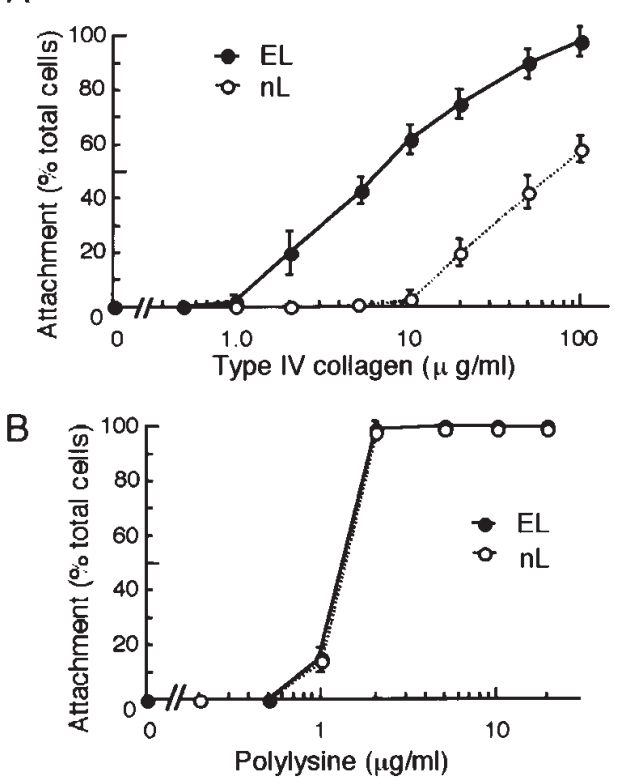

Figure 1. EL cells demonstrate enhanced attachment to type IV collagencoated, but not to polylysine-coated, substrata. (A) Enhanced attachment to type IV collagen-coated substrata. Tissue culture plates were coated with varying concentrations of type IV collagen, as described in Materials and methods. EL and $\mathrm{nL}$ cells pre-labeled with ${ }^{35} \mathrm{~S}$, were dissociated, resuspended, and allowed to adhere to plates for $2 \mathrm{~h}$. Adherent cells were recovered and analyzed for radioactivity. Abscissa, concentration of type IV collagen $(\mu \mathrm{g} / \mathrm{ml})$; ordinate, $\%$ cells adhered. Although we only present the results obtained with one representative clone of each transfectant, analyses of two additional clones of each transfectant gave similar results. The error bars represent SDs. (B) Attachment to polylysine. Substrata were prepared by coating tissue culture plates with varying concentrations of polylysine. Cells were allowed to adhere to the substrata for $1 \mathrm{~h}$

used as control cells. E-cadherin expression caused a marked enhancement of $\mathrm{L}$ cell attachment to substrata coated with low concentrations of type IV collagen (Fig. 1A); the overall efficiency of the use of this matrix protein was enhanced. Noticeably, there was an approximate one log left shift in the dose-response curve of cell adhesion to type IV collagen. Expression of E-cadherin also causes an approximately 4-fold increase in the rate of adhesion of L cells to type IV collagencoated substrata (Fig. 2).

E-cadherin expression affects integrin-mediated, but not nonspecific, adhesion. We investigated whether the effect of E-cadherin expression on adhesion was restricted to type IV collagen-mediated adhesion or whether adhesion processes to other substrata were also affected. We determined whether Ecadherin expression caused diverse effects on cell membrane structure that might result in non-specific adhesion to multiple types of substratum. To approach these questions, we examined the adhesion of $\mathrm{L}$ cells to substrata coated with polylysine, a situation in which non-specific cell attachment would probably occur. The adhesion of control L or EL cells to non-specific polylysine-coated substrata was virtually identical (Fig. 1B), suggesting that E-cadherin expression did not affect nonspecific adhesion. Similar experiments utilizing fibronectin, laminin, and type I collagen as ECM revealed that Ecadherin expression caused a marked enhancement in the ability of L cells to attach to substrata coated with low

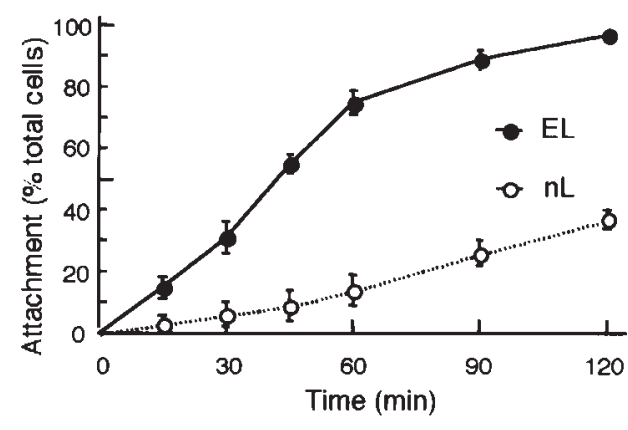

Figure 2. EL cells exhibited attachment to type IV collagen with faster kinetics than L cells. Tissue culture plates were coated with $100 \mu \mathrm{g} / \mathrm{ml}$ of type IV collagen, then blocked with BSA. Cells were allowed to attach at $37^{\circ} \mathrm{C}$ for different time intervals.

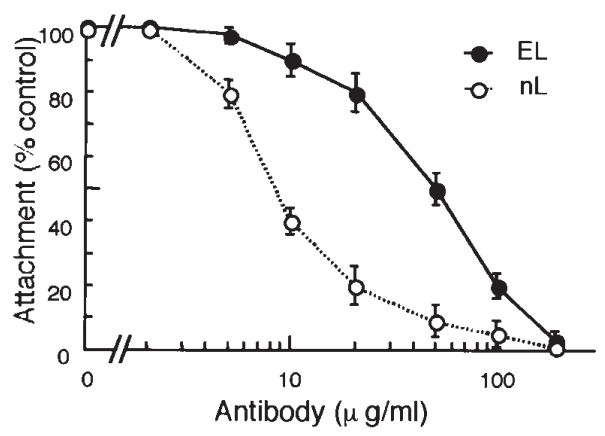

Figure 3. Integrin antibodies inhibit EL and $\mathrm{nL}$ cell attachment to type IV collagen. Cells were preincubated with the indicated concentrations of antibodies for $30 \mathrm{~min}$ at $4^{\circ} \mathrm{C}$, then allowed to attach to plates coated with type IV collagen $(100 \mu \mathrm{g} / \mathrm{ml})$ for $2 \mathrm{~h}$ at $37^{\circ} \mathrm{C}$.

concentrations of ECM components; the overall efficiency of the use of these matrix proteins was enhanced (data not shown).

Effects of E-cadherin expression on the potency of antireceptor antibodies. We next investigated the influence of E-cadherin expression on the inhibition of cell adhesion to type IV collagen produced by anti-receptor antibodies. Ecadherin expression caused a marked right shift in the doseresponse curve for inhibition by anti-receptor antibodies (Fig. 3); the $\mathrm{IC}_{50}$ shifted from $9 \mu \mathrm{g} / \mathrm{ml}$ for $\mathrm{nL}$ cells to $50 \mu \mathrm{g} / \mathrm{ml}$ for EL cells. Thus, EL cells exhibited reduced sensitivity to anti-receptor antibody inhibition of adhesion. These results, in conjunction with those of Fig. 1, are consistent with an increase in the number of cell surface integrins following enhanced E-cadherin expression. As indicated below, however, this is apparently not the case.

EL cells show enhanced spreading to type IV collagen. Integrinmediated cell-substrate interactions are often accompanied by cell spreading, a flattening of the cell that increases the surface area in contact with the ECM, thereby facilitating stronger adhesion. Having demonstrated that E-cadherin expression enhanced integrin-mediated attachment to the ECM, we investigated whether E-cadherin expression is important for cell spreading by phase contrast microscopy. The majority of EL cells exhibited an adherent spread morphology, 


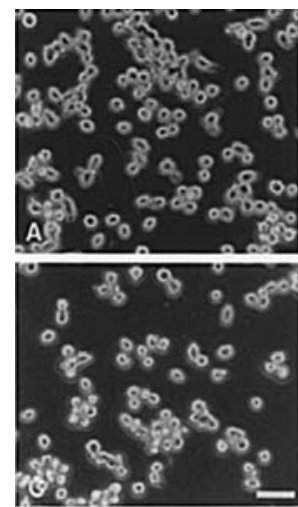

$\mathrm{nL}$ cells

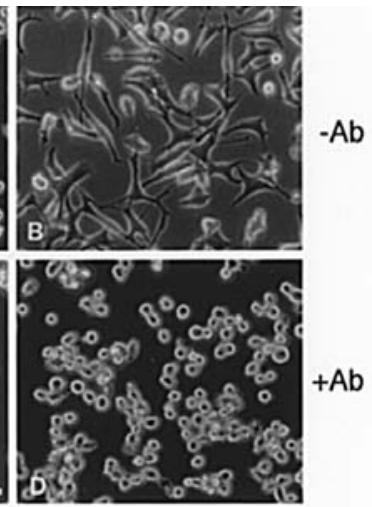

EL cells
Figure 4. EL cells exhibit enhanced spreading on type IV collagen. Cells were allowed to adhere to plates coated with type IV collagen $(100 \mu \mathrm{g} / \mathrm{ml})$ for $2 \mathrm{~h}$ at $37^{\circ} \mathrm{C}$. Phase-contrast micrographs demonstrate the spreading of EL cells, but not $\mathrm{nL}$ cells. Treatment with anti-integrin antibodies $(100 \mu \mathrm{g} / \mathrm{ml})$ inhibited the attachment and spreading of EL cells (lower panels, $+\mathrm{Ab}$ ). The majority of $\mathrm{nL}$ cells remained round and loosely attached to the substrate; only a few cells demonstrated limited spreading. In contrast, the majority of EL cells exhibited spreading.

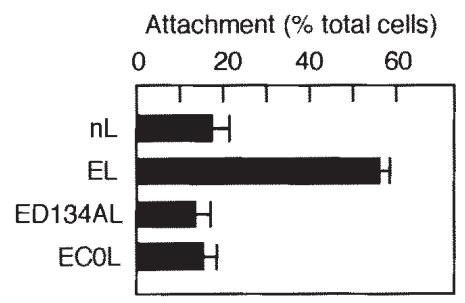

Figure 5. Cells expressing either a non-functional or tail-less E-cadherin do not show enhanced attachment to type IV collagen-coated dishes. ED134L cells express a mutant E-cadherin molecule with a substitution of the aspartic acid at position 134 in the $\mathrm{Ca}^{2+}$-binding motif with alanine, which is not functional in aggregation assays. ECOL cells express a tail-less E-cadherin form that lacks the entire cytoplasmic domain. Cells were allowed to attach to dishes coated with type IV collagen $(100 \mu \mathrm{g} / \mathrm{ml})$ for $2 \mathrm{~h}$ at $37^{\circ} \mathrm{C}$.

appearing darker by phase-contrast microscopy and having several membrane projections (Fig. 4B). When EL cells were incubated with anti-receptor antibodies, spreading was inhibited; the cells displayed a round and detached morphology (Fig. 4D). In contrast to EL cells, nL cells tended to be uniformly round cells that did not adhere to type IV collagencoated dishes, only rarely taking on a spread phenotype (Fig. 4A). Thus, the poor attachment of $\mathrm{nL}$ cells to type IV collagen was reflected in their inability to flatten and spread on this substrate.

Cells expressing a non-functional or tail-less E-cadherin construct do not exhibit enhanced attachment to type IV collagen-coated dishes. To confirm that the enhanced attachment of E-cadherin-expressing L cells was dependent on E-cadherin, we established two additional cell clones expressing mutant forms of E-cadherin. ED134AL cells express a mutant E-cadherin bearing an amino acid substitution in the $\mathrm{Ca}^{2+}$-binding motif (ED134A); an aspartic acid at residue 134 was replaced with alanine, which results in a loss of adhesive activity in L cells (29). ECOL cells express a second mutant

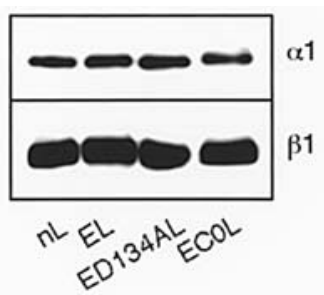

Figure 6. Immunoblot analysis of integrin subunits. Cells were lysed in SDSsample buffer, subjected to SDS-PAGE, and examined by immunoblotting with the indicated antibodies.

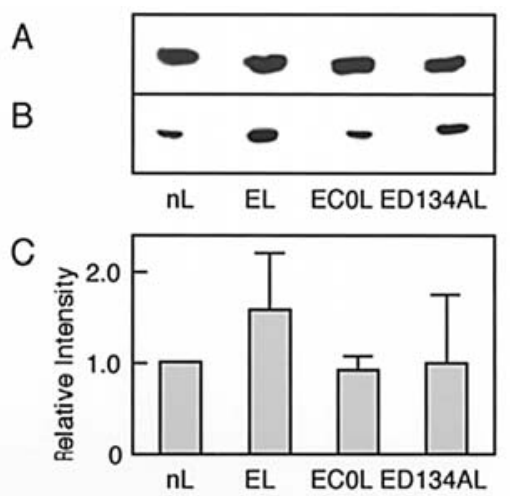

Figure 7. EL cells exhibit increased levels of activated Rac1. Cells were lysed in lysis buffer; the lysates were incubated with GST-CRIB. Proteins bound to GST-CRIB were subjected to SDS-PAGE and immunoblotting with antiRac antibody (B). The upper panel (A) displays the levels of total Rac1 protein. (C) Quantification of Rac activation in nL, EL, EC0L, and ED134AL cells is shown. Rac activation is expressed as a value normalized to the levels seen in control $\mathrm{nL}$ cells, which were arbitrarily set as 1 . The results represent the mean \pm SE of three experiments. Error bars represent SDs.

E-cadherin with a complete deletion of the cytoplasmic domain (28). This mutant form of E-cadherin cannot associate with catenins, but is functional in cell aggregation (28). L cells expressing either of these mutant E-cadherin proteins did not display any enhanced attachment to type IV collagen (Fig. 5). Thus, both the cytoplasmic domain and a functional $\mathrm{Ca}^{2+}$ binding motif are required for the enhanced attachment to type IV collagen.

Cell adhesion receptors on $\mathrm{L}$ cells have not been extensively studied. To demonstrate that the enhanced attachment and spreading of EL cells on type IV collagen results from increased levels of integrins, we examined $\beta 1$ integrin expression. Immunoblot analysis using an anti-mouse $B 1$ integrin antibody indicated equal levels of expression in EL, $\mathrm{nL}$, ED134AL, and ECOL cells (Fig. 6). The amount of $\alpha 1$ integrin, a collagen receptor, also did not differ among these cells. Thus, E-cadherin expression does not affect the amount of integrins expressed by $L$ cell variants.

E-cadherin expression increased the amount of activated Racl. As it has been demonstrated that Rho family GTPases play important roles in the regulation of integrin clustering and the subsequent interaction of integrins with focal adhesion molecules, we examined the activation state of these proteins in EL, nL, ED134AL, and ECOL cells. GST-CRIB specifically 
interacts with activated (GTP-bound) Rac1 and Cdc42, which can allow the determination of the levels of these activated molecules in cells (31). Pull-down assays utilizing GST-CRIB revealed increased Rac-GTP levels in cells expressing wildtype E-cadherin in comparison to $\mathrm{L}$ or $\mathrm{nL}$ cells. ED134AL and ECOL cells did not display this increase in activated Rac levels (Fig. 7). We did not observe a significant difference in the amount of total Rac1 in lysates between these cells. In contrast to Rac1, the levels of active RhoA did not differ between these cells, as measured by GST-RBD pull-down (data not shown). No active Cdc42 could be detected using GST-CRIB under the conditions employed (data not shown). These results suggest that Rac1 is specifically activated in EL cells that express E-cadherin.

\section{Discussion}

EL cells adhered more rapidly and efficiently to substrata coated with the extracellular matrix protein type IV collagen. Adhesion to type IV collagen involved a specific, integrintype membrane receptor, as it was inhibited by anti-receptor antibodies. Adhesion to non-specific substrata, such as polylysine, was not noticeably affected by E-cadherin expression. Thus, the effects of E-cadherin expression involved the stimulation of receptor-mediated adhesion, but did not induce global changes in membrane behavior leading to increased non-specific adhesion. The efficiency of ligand-mediated adhesion was enhanced in EL cells (i.e., the dose-response curve for ligand is shifted to the left), while the potency of specific inhibitors of adhesion was decreased (the curve for inhibitor is right-shifted). This result suggests that E-cadherin expression results in an increase in the number and/or affinity of the specific ligand receptor. Immunoblot analysis demonstrated that E-cadherin expression had no effect on the amount of integrin. Thus, the effect of E-cadherin expression on integrin-mediated cell adhesion does not appear to alter the abundance of the receptor, but instead modulates events subsequent to initial ligand-receptor binding. This phenomenon is similar to regulation of cell adhesion by cAMP-dependent kinase or protein kinase $\mathrm{C}(33,34)$, which occurs at the postreceptor level. This regulation, however, differs from the tyrosine kinase regulation of adhesion, which directly affects the binding characteristics of the fibronectin receptor $(1,35)$.

Links between cadherins and integrins in various normal cell types have previously been reported. Xenopus-derived fibroblasts transfected with E-cadherin demonstrated reduced adhesion to fibronectin and laminin as a consequence of integrin downregulation (24), while the expression of dominantnegative E-cadherin within the intestines of transgenic mice led to a reduction in cellular substrate adhesion (36). In quail myoblasts, transfection of the $\alpha 5$ integrin subunit increased $\mathrm{N}$-cadherin expression and function (37). In contrast, inhibition of adherence to fibronectin via blockade of $\beta 1$ and $\beta 3$ integrin subunits increased $\mathrm{N}$-cadherin-mediated cell-cell adhesion between neural crest cells (26). Our studies confirm the interactions between members of the cadherin and integrin adhesion receptor families in mouse fibroblast L cells. Expression of wild-type, but not mutant, E-cadherin molecules resulted in enhanced adhesion of the cells to dishes coated with extracellular matrix components.
It was recently reported that the engagement of E-cadherins by homophilic cell-cell interactions resulted in rapid PI3kinase activation (38) and the recruitment and activation of Rac1 $(31,39)$. E-cadherin-mediated cell-cell adhesion induces Cdc42 activation following stable expression in L cells (40). Activation of the Rho family of small GTPases triggers the assembly of focal complexes when activated in cells; both matrix components and functionally active members of the Rho family are absolutely required for focal complex formation (18). During adhesion to the ECM, neither Rho nor Rac affect integrin affinity (41). In cells such as fibroblasts, both of these proteins induce integrin clustering, increasing the strength of adhesion (41). Thus, the integrin clustering may be responsible for the observed enhancement of adhesion to the ECM. Furthermore, the Rho family of GTPases, including $\mathrm{Rac} 1, \mathrm{Cdc} 42$, and RhoA, regulate reorganization of the actin cytoskeleton $(42,43)$. Rac is also involved in the recruitment of actin to the cell cortex in fibroblasts (44). Therefore, the observed enhancement of adhesion to the ECM may occur by a reorganization of actin cytoskeleton that is mediated by Rac1 activation. Further studies are needed to elucidate the molecular mechanism responsible for these observations.

\section{Acknowledgments}

This work was supported by Grants-in-Aid for Science Research from the Japan Society for Promotion of Science and a Grant-in-Aid for Science Research on a Priority Area from the Ministry of Education, Culture, Sports, Science, and Technology of Japan.

\section{References}

1. Buck CA and Horwitz AF: Cell surface receptors for extracellular matrix macromolecules. Annu Rev Cell Biol 3: 179-205, 1987.

2. Giancotti FG and Tarone G: Positional control of cell fate through joint integrin/receptor protein kinase signaling. Annu Rev Cell Dev Biol 19: 173-206, 2003.

3. Hynes RO: Integrins: a family of cell surface receptors. Cell 48 : 549-554, 1987.

4. Ruoslahti E and Pierschbacher MD: New perspectives in cell adhesion: RGD and integrins. Science 238: 491-497, 1987.

5. Brown PJ and Juliano RL: Monoclonal antibodies to a cell surface glycoprotein selectively inhibit fibronectin mediated cell adhesion. Science 228: 1448-1451, 1985.

6. Pytela R, Pierschbacher MD and Ruoslahti E: Identification and isolation of a $140 \mathrm{kd}$ cell surface glycoprotein with properties expected of a fibronectin receptor. Cell 40: 191-198, 1985.

7. Takada YE, Wayner A, Carter WG and Hemler ME: Extracellular matrix receptors ECMRII and ECMRI correspond to VLA-2 and VLA-3 in the VLA family of heterodimers. J Cell Biochem 37: 385-393, 1988.

8. Wayner ER and Carter WG: Identification of multiple cell adhesion receptors for fibronectin in human fibrosarcoma cells expressing unique alpha and common beta subunits. J Cell Biol 105: 1873-1884, 1987.

9. Ruoslahti E and Pierschbacher MD: Arg-gly-asp: a versatile cell recognition signal. Cell 44: 517-518, 1986.

10. Hunter T: A thousand and one protein kinases. Cell 50: 823-829, 1987.

11. Krebs E: The enzymology of control of phosphorylation. The Enzymes 17: 3-20, 1986.

12. Faull RJ, Kovach NL, Harlan JM and Ginsberg MH: Stimulation of integrin-mediated adhesion of T lymphocytes and monocytes: two mechanisms with divergent biological consequences. J Exp Med 179: 1307-1316, 1994.

13. Stewart M and Hogg N: Regulation of leukocyte integrin function: affinity vs. avidity. J Cell Biochem 61: 554-561, 1996.

14. Stuiver I and O'Toole TE: Regulation of integrin function and cellular adhesion. Stem Cells 13: 250-262, 1995. 
15. Van Aelst L and D'Souza-Schorey C: Rho GTPases and signaling networks. Genes Dev 11: 2295-2322, 1997.

16. Ridley AJ and Hall A: The small GTP-binding protein rho regulates the assembly of focal adhesions and actin stress fibers in response to growth factors. Cell 70: 389-399, 1992.

17. Ridley AJ, Paterson HF, Johnston CL, Diekmann D and Hall A The small GTP-binding protein rac regulates growth factorinduced membrane ruffling. Cell 70: 401-410, 1992.

18. Hotchin NA and Hall A: The assembly of integrin adhesion complexes requires both extracellular matrix and intracellular rho/rac GTPases. J Cell Biol 131: 1857-1865, 1995.

19. Hughes PE, Renshaw MW, Pfaff M, Forsyth J, Keivens VM, Schwartz MA and Ginsberg MH: Suppression of integrin activation: a novel function of a Ras/Raf-initiated MAP kinase pathway. Cell 21: 521-530, 1997.

20. Takeichi M: The cadherins: cell-cell adhesion molecules controlling animal morphogenesis. Development 102: 639-655, 1988.

21. Ozawa M, Baribault $\mathrm{H}$ and Kemler R: The cytoplasmic domain of the cell adhesion molecule uvomorulin associates with three independent proteins structurally related in different species. EMBO J 8: 1711-1717, 1989.

22. Ozawa M, Ringwald M and Kemler R: Uvomorulin-catenin complex formation is regulated by a specific domain in the cytoplasmic region of the cell adhesion molecule. Proc Natl Acad Sci USA 87: 4246-4250, 1990.

23. Hodivala KJ and Watt FM: Evidence that cadherins play a role in the downregulation of integrin expression that occurs during keratinocyte terminal differentiation. J Cell Biol 124: 589-600, 1994.

24. Finnemann S, Kühl M, Otto G and Wedlich D: Cadherin transfection of Xenopus XTC cells downregulates expression of substrate adhesion molecules. Mol Cell Biol 15: 5082-5091, 1995.

25. Zhu AJ and Watt FM: Expression of a dominant-negative cadherin mutant inhibits proliferation and stimulates terminal differentiation of human epidermal keratinocytes. J Cell Sci 109: 3013-3023, 1996.

26. Monier-Gavelle F and Duband JL: Cross talk between adhesion molecules: control of $\mathrm{N}$-cadherin activity by intracellular signals elicited by $\beta 1$ and $\beta 3$ integrins in migrating neural crest cells. J Cell Biol 137: 1663-1681, 1997.

27. Ozawa M, Sato M, Muramatsu H, Hamada H and Muramatsu T: A membrane glycoprotein involved in teratocarcinoma cell adhesion to substratum. Exp Cell Res 158: 127-143, 1985.

28. Ozawa M and Kemler R: The membrane-proximal region of the E-cadherin cytoplasmic domain prevents dimerization and negatively regulates adhesion activity. J Cell Biol 142: 1605-1613, 1998.

29. Ozawa M and Kemler R: Altered cell adhesion activity by pervanadate due to the dissociation of $\alpha$-catenin from the Ecadherin-catenin complex. J Biol Chem 273: 6166-6170, 1998.
30. Ozawa M: p120-independent modulation of E-cadherin adhesion activity by the membrane-proximal region of the cytoplasmic domain. J Biol Chem 278: 46014-46020, 2003.

31. Nakagawa M, Fukata M, Yamaga M, Itoh $\mathrm{N}$ and Kaibuchi K: Recruitment and activation of Racl by the formation of Ecadherin-mediated cell-cell adhesion sites. J Cell Sci 114: 1829-1838, 2001.

32. Nagafuchi A, Shirayoshi Y, Okazaki K, Yasuda K and Takeichi M: Transformation of cell adhesion properties by exogenously introduced E-cadherin cDNA. Nature 329: 341-343, 1987.

33. Cheung E and Juliano RL: cAMP induced phenotypic reversion of adhesion, aggregation, and endocytosis in adhesion defective CHO cell variants. J Cell Physiol 124: 337-343, 1985.

34. Danilov YN and Juliano RL: Phorbol ester modulation of integrin-mediated cell adhesion: a postreceptor event. J Cell Biol 108: 1925-1933, 1989.

35. Hirst R, Horwitz AF, Buck C and Rohrschneider L: Increased phosphorylation of the fibronectin receptor complex in cells transformed by oncogenes that encode tyrosine kinases. Proc Natl Acad Sci USA 83: 6470-6474, 1986.

36. Hermiston ML and Gordon JI: In vivo analysis of cadherin function in the mouse intestinal epithelium: essential roles in adhesion, maintenance of differentiation, and regulation of programmed cell death. J Cell Biol 129: 489-506, 1995.

37. Huttenlocher A, Lakonishok M, Kinder M, Wu S, Truong T, Knudsen KA and Horwitz AF: Integrin and cadherin synergy regulates contact inhibition of migration and motile activity. $\mathbf{J}$ Cell Biol 141: 515-526, 1998.

38. Pece S, Chiariello M, Murga C and Gutkind JS: Activation of the protein kinase $\mathrm{Akt} / \mathrm{PKB}$ by the formation of E-cadherinmediated cell-cell junctions. Evidence for the association of phosphatidylinositol 3-kinase with the E-cadherin adhesion complex. J Biol Chem 274: 19347-19351, 1999.

39. Betson M, Lozano E, Zhang J and Braga VM: Rac activation upon cell-cell contact formation is dependent on signaling from the epidermal growth factor receptor. J Biol Chem 277: 36962-36969, 2002 .

40. Kim SH, Li Z and Sacks DB: E-cadherin-mediated cell-cell attachment activates Cdc42. J Biol Chem 275: 36999-37005, 2000.

41. Burridge $\mathrm{K}$ and Wennerberg K: Rho and Rac take center stage. Cell 116: 167-179, 2004.

42. Hall A: Rho GTPases and the actin cytoskeleton. Science 279: 509-514, 1998.

43. Kaibuchi K, Kuroda S and Amano M: Regulation of the cytoskeleton and cell adhesion by the Rho family GTPases in mammalian cells. Annu Rev Biochem 68: 459-486, 1999.

44. Machesky LM and Hall A: Role of actin polymerization and adhesion to extracellular matrix in Rac- and Rho-induced cytoskeletal reorganization. J Cell Biol 138: 913-926, 1997. 